\title{
Acoustic Analysis of Machineries in the Cement Industry
}

\author{
Alireza Noorpoor, Ali Ahmadi Orkomi* \\ Graduate Faculty of Environment, University of Tehran, Tehran, Iran \\ Email: ${ }^{*}$ Orkomi@ut.ac.ir
}

Received 22 April 2014; revised 20 May 2014; accepted 19 June 2014

Copyright (C) 2014 by authors and Scientific Research Publishing Inc.

This work is licensed under the Creative Commons Attribution International License (CC BY). http://creativecommons.org/licenses/by/4.0/

(c) (i) Open Access

\begin{abstract}
A study has been conducted at the Tehran cement factory to recognize and analyze the major noise emission source machineries. Cement industry has many process units. Basically all of these units or stages can be considered as a source of noise. Since noise pollution is defined based on its offensive hearing effects, the importance of the noise sources depends directly on the number of workers in the unit. In this survey, first, the mean A-weighted sound pressure level and number of the workers in each unit have been measured and the obtained data were analyzed in Microsoft Excel. The noisiest units have been recognized and some applicable suggestions offered to reduce the sound exposure level. Afterwards, based on the mentioned ISO, some experiments have been done to calculate the A-weighted acoustic power level of the crusher which emitted the highest level of noise. By calculating the sound power levels and considering the affecting design parameters on the sound power generated by the crusher, an empirical equation has been presented to calculate the acoustic power level as a function of physical parameters horsepower, number of hammers and the weight of each hammer.
\end{abstract}

\section{Keywords}

Sound Pressure Level, Measurement, Cement Industry, Sound Power Level, Design Parameters

\section{Introduction}

Noise is one of the physical environmental factors affecting human health. Because of the adverse effects on the people life in the large and industrial cities, it is becoming a remarkable concern. Noise in work environment is the major cause of concern for safety and health of the factory workers. Regulations limiting noise exposure to industrial workers have been instituted in different countries [1] [2]. The aim of these noise regulations is to en-

"Corresponding author.

How to cite this paper: Noorpoor, A. and Orkomi, A.A. (2014) Acoustic Analysis of Machineries in the Cement Industry. Open Journal of Safety Science and Technology, 4, 98-105. http://dx.doi.org/10.4236/ojsst.2014.42011 
sure that workers' hearing is protected from excessive noise at their place of work, which could cause them to lose their hearing or to suffer from tinnitus. Noise in work environment is the major cause of concern for safety and health of the factory workers. Industrial laws in many countries provide protection to workers from noise pollution as described by the National Environmental Standards Committee of the Tanzanian Bureau of Standards (TBS) [3]. Exposure duration of $40 \mathrm{hr}$ per week of equivalent noise level of $85 \mathrm{dBA}$ is considered to be safe and noise level above this limit is bound to cause noise induced temporary or permanent hearing loss [4]-[6]. Cement manufacturing is one of the major areas that play a significant role in economy of countries. Sharma et al. [7] compared experimental sound pressure level (SPL) with the calculated SPL by proposed formula and related the exposed SPL to the horsepower and the life time of the source. Also some research has been done on measuring the noise level in cement plants, analyzing the hearing damage on labors and providing some noise control suggestions to reduce the bad effects of noise exposure [8]-[10]. With the aim of noise generation parameters recognition, a vast research has been done [11] [12]. Makarewicz [13] and Jones and Hothersall [14] studied the effective parameters on road vehicle noise generation. The cement production machineries emit offensive noise because they have a high acoustic power. In the design point of view, to investigate the sensitivity of the emitted noise to the physical parameters, the influence of the parameters on the sound power level should be conducted. But based on the writers' knowledge, the effect of design parameters on cement machineries noise emission has not been published well. In this work an experimental survey has been done in Tehran cement plant to demonstrate the most noise emission sources. To overcome the aforementioned drawbacks in recognition of the affecting parameters on the acoustic power level, an empirical equation has been presented to correlate the sound power level of the crusher to its design variables. The paper is organized as follows. In the Section 2.1, the method and the algorithm of sound level measurement have been emphasized. In the next one, sound level measurement result has been reported. In Section 2.2 the correlation between sound power level and some key effecting parameters has been discussed. Some conclusion remarks have been highlighted in the Section 3.

\section{Methods and Measuring Strategies}

This work has been conducted at the Tehran cement factory. The Tehran cement factory is one of the highest ranking cement producers in Iran and its product is type 2 Portland cement. Based on the writers' knowledge, studies about the noise pollution from machinery and the noise exposure rate in the workers zones have not been well established for this industrial plant. A schematic diagram of the main process units in a cement factory has been shown in Figure 1 and the overall map of the cement plant has been demonstrated in Figure 2.

All measurement procedures were according to the ISO 3746 [15] and the noise levels were measured by a digital mini sound pressure level meter (MODEL TES 1353H) in the workers main commuting spots. The measurements have been done during the work hours on July 20, 2013, between 11.00 am and 4.00 pm, in which all of the major machines were running and the number of workers was maximum.

\subsection{Measurements for Exposure Purpose}

First the number of units and the measuring areas in each unit has been chosen based on the noted ISO algorithm. The measuring units in the plant are main stone crusher, row material mill, pre heater, kiln, kiln to cement mill conveyer line, cement mill and packing unit. These units also have been tagged in Figure 2. To obtain a better

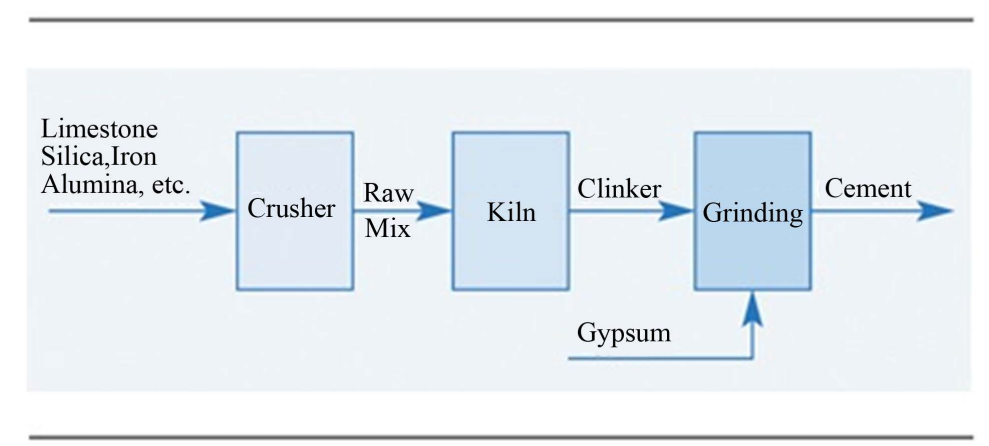

Figure 1. Schematic diagram of process units in a cement factory. 


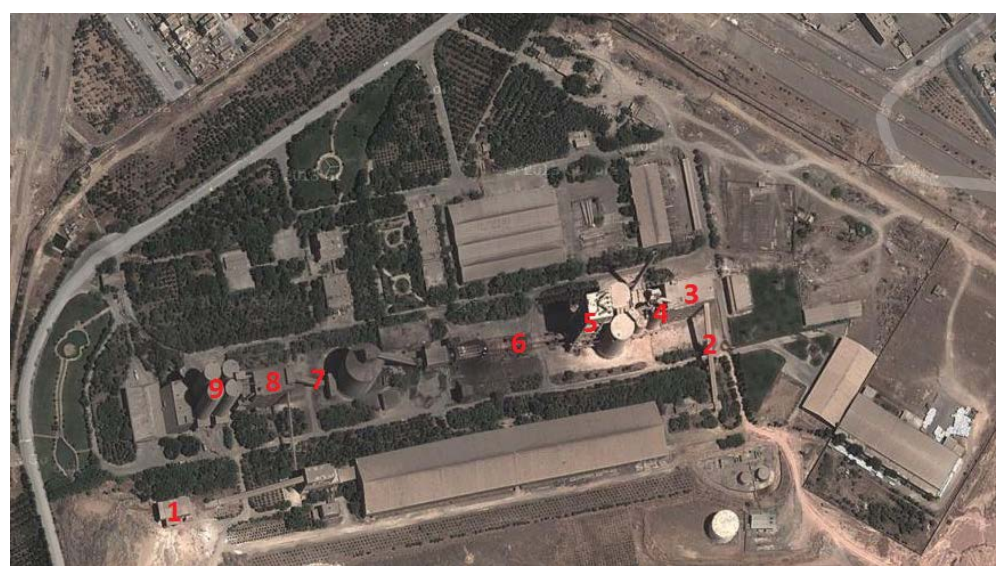

Figure 2. Top view of Tehran cement plant with tagged SPL measuring areas.

and more reliable data, for the large areas, the number of measuring point was increased. Some of units in this plant have more than three floors. For example in the row material mill there is a separate floor for the mill, gearboxes and centrifugal separators. So in such a unit to obtain a remarkable and tangible result, the measurement has been done on the all floors separately. In all measurement points the sound level meter has been set toward the mentioned unit and 60 centimeters away from operator. Regarding to the number of measurement in a unit, the logarithmic average of the data has been obtained and reported as the mean sound pressure level of the unit. The result of all measurement executed, has been demonstrated in Table 1. It should be note that the units' numbers in Table 1 and the tagged numbers in Figure 2 are identical.

By using the data in Table 1, the most infamous noise emission sources in this factory are summarized in Table 2. According to Table 1 and Table 2, it can be concluded that the noisiest source is the crusher unit with the mean SPL 102.4 dB at its basement. Among the nine units, the packing unit, kiln to cement mill and crusher to row mill conveyers, kiln and pre heater have the equivalent sound pressure level $\left(\mathrm{L}_{\mathrm{Aeq}}\right)$ lower than $85 \mathrm{~dB}$. So they are acoustically the safe zones for the labors. But in the high noise exposure units, there is major risk of hearing loss for the operators. Although the workers in these units use hearing protection gears, it is not an efficient control strategy. Because, despite using the gears, the labors in these zones, have a sound lever induced hearing damages. Based on the measured level of noise in the factory, to reduce the level of hearing damages, the following policies are recommended:

- Feasibility study of different control strategy and select the one that is effective and affordable.

- Check the performance of the major equipment periodically, in order to troubleshooting ant fix the problem by lubricating, repairing and etc.

- Reduce the noise exposure level of the labors by employing part time operators or altering their activity zones between safe and unsafe acoustical zones.

It should be noted that the mentioned recommendations is for this factory and for the other factories, based on the specific conditions, the feasibility of these policies can be change. The noise emitted from the noted units in the Tehran cement factory can be harmful for the people in the surrounding residential zones. As can be seen generally in Figure 2, by planting trees around the factory, the noise level has been reduced to a tolerable level at the residential area.

As noted in the preceding paragraphs, in this survey, the crusher unit has emitted the maximum level of noise in the plant. As can be seen in previous published works [10] [16], this unit is one of the top ranked noise pollution sources. So regardless to the type of stone in different factories, this unit naturally is a main source of noise. In this regard, it cannot be a rough idea to consider the designing parameters as the main cause of noise emission. So in the following section it has been tried to correlate the emitted noise of the crusher unit to its physical parameters.

\subsection{Measurements for Obtaining Sound Power Level}

The pressure level of a source can be measured directly and easily, but until now, there is not a devise or algorithm to measure the sound power level of an acoustic source directly. The importance of the sound power level became from design and noise control point of view. The pressure level of a distinct source depends on the fea- 
tures of the environment in which the sound transmitted and it is different for a noise source in two different media. Then the SPL cannot be a sound feature for design purposes. In contrast, the sound power level is only a function of the design and operational parameters of the sound source. So if the value of sound power level is calculated, by correlating the power level with the physical parameters (like power, frequency, size, constructing materials and etc.), a machine with a lower value of emitted sound power level can be designed by altering the affecting parameters.

In this work, an empirical relationship correlates the sound power level of crusher unit to some independent effective physical parameters. In approaching to the aforementioned purpose, the value of sound power level was calculated in some different values of independent variables. The sound power level was calculated from SPL data. According to Barron [17], the method of calculation of the sound power level from SPL data depends on the space in which the source is located. If the desired environment is an ideal reverberant or an anechoic room, some national and international standards like ANSI S1.31, ANSI S1.32, ANSI S1.33 and ANSI S1.35 [18]-[21] and ISO 3741, ISO 3742, ISO 3743 and ISO 3745 [22]-[25] for measuring the SPL has been developed. In this work the environment was not an ideal reverberant or anechoic room. So for this real room, the survey method established by ANSI S1.36 [26] and ISO 3746 [15] has been applied.

Hear one microphone has been used for measurement. According to the survey method, there are nine key measurement points around the source as depicted in Figure 3.

Table 1. SPL values and the number of labors in noisy units of the cement plant.

\begin{tabular}{|c|c|c|c|c|c|c|}
\hline & Unit & Sample No. & Labor No. & SPL-L $\mathrm{L}_{\text {Aеq }}$ & SPL-max & SPL-min \\
\hline \multirow{3}{*}{1} & Crusher (Ground) & 14 & \multirow{3}{*}{2} & 102.4 & 105 & 98 \\
\hline & Crusher (Underground-1) & 4 & & 98.9 & 101 & 97 \\
\hline & Crusher (Underground-2) & 2 & & 87 & 88 & 86 \\
\hline \multirow[t]{2}{*}{2} & Conveyor (Crusher to Raw Mill) & 4 & \multirow[t]{2}{*}{1} & 78.1 & 80 & 76.3 \\
\hline & Raw Mill—First Floor (Gearbox Unit) & 16 & & 99.15 & 103.3 & 93 \\
\hline \multirow{3}{*}{3} & Raw Mill—Second Floor & 6 & \multirow{3}{*}{3} & 92 & 94.1 & 88 \\
\hline & Raw Mill—Third Floor (Separators) & 3 & & 82.8 & 83 & 82.5 \\
\hline & Raw Mill—Fourth Floor (Gearbox Elevators) & 6 & & 87.1 & 88.9 & 86.8 \\
\hline 4 & Raw Mill Blower & 7 & 1 & 98.8 & 101 & 98 \\
\hline 5 & Pre heater & 6 & 8 & 86.2 & 87 & 81 \\
\hline 6 & Kiln & 6 & 1 & 80 & 80.1 & 78 \\
\hline 7 & Conveyor (Kiln to Cement Mill) & 3 & 1 & 81 & 81.5 & 80 \\
\hline \multirow{4}{*}{8} & Cement Mill—First Floor (Gearbox Unit) & 12 & \multirow{4}{*}{2} & 100.83 & 103.8 & 99.3 \\
\hline & Cement Mill—Second Floor & 4 & & 98.9 & 100 & 98 \\
\hline & Cement Mill—Third Floor & 6 & & 88 & 89 & 85 \\
\hline & Cement Mill—Fourth Floor(Separators) & 6 & & 84.1 & 85 & 83.3 \\
\hline 9 & Packing Unit & 8 & 16 & 81 & 85 & 79.2 \\
\hline
\end{tabular}

Table 2. Most noisy units in the Tehran cement factory.

\begin{tabular}{cc}
\hline Unit Name & SPL- $\mathrm{L}_{\text {Aeq }}$ \\
\hline Crusher (Ground) & 102.4 \\
Cement Mill_First Floor (Gearbox Unit) & 100.83 \\
Raw Mill—First Floor (Gearbox Unit) & 99.15 \\
Crusher (Underground-1) & 98.9 \\
Cement Mill—Second Floor & 98.9 \\
Raw Mill Blower & 98.8 \\
\hline
\end{tabular}




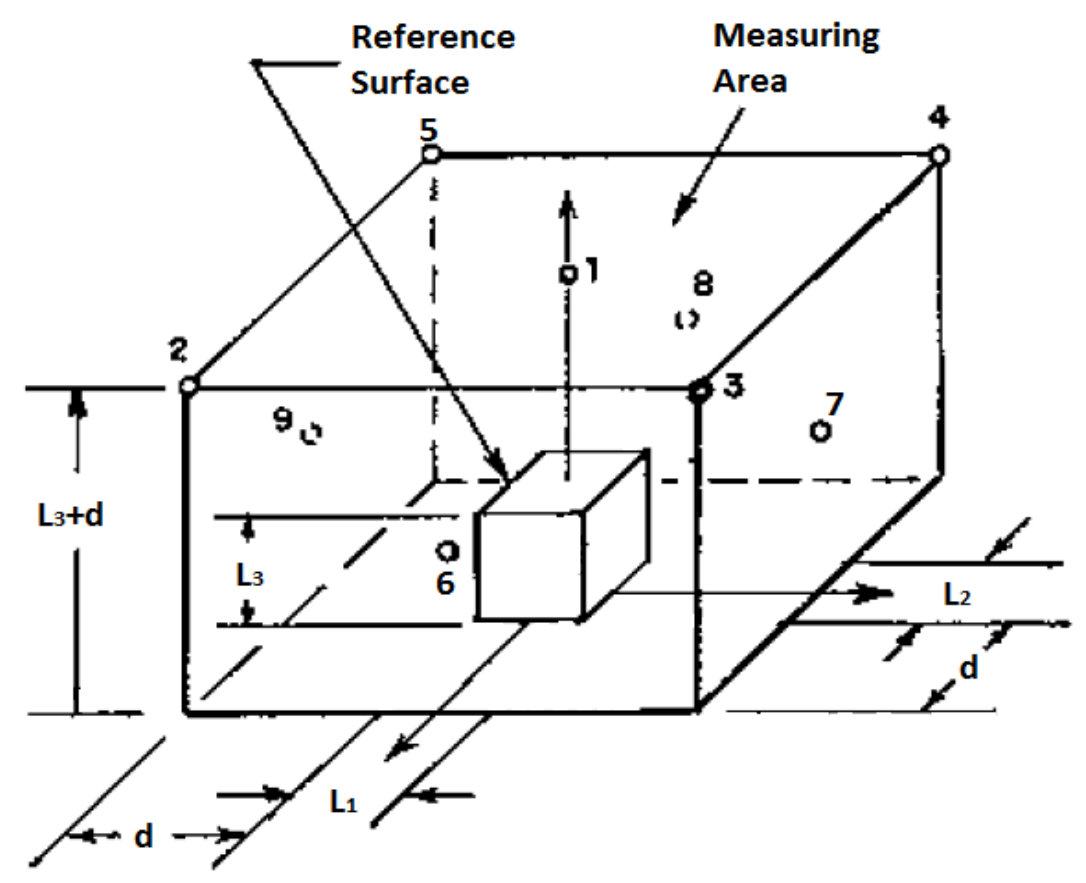

Figure 3. Key measuring points around a noise source in the survey method.

According on the survey algorithm described in Barron [17], the values of constants in Figure 3 can be selected based on the dimension of the source. The acoustic intensity for a direct and reverberant acoustic energy can be formulated as below,

$$
W\left(\frac{4}{R}+\frac{1}{S_{m}}\right)=\frac{W}{S_{m}}\left(\frac{4 S_{m}}{R}+1\right)=\frac{P_{a v e}^{2}}{\rho c}
$$

where $P_{a v e}$ is the energy averaged sound pressure and is defined as $P_{a v e}^{2}=\sum_{=1}^{9} P_{i}^{2} / 9$ and $S_{m}$ is the virtual enclosed surface in Figure 1 and is defined below,

$$
S_{m}=2((l 1+2 d) *(l 2+2 d)+(l 3+d) *((l 1+2 d)+(l 2+2 d)))
$$

$R$ is the room constant and may be calculated from Equation (3).

$$
R=\frac{\bar{\alpha} \cdot S_{0}}{1-\bar{\alpha}}
$$

in which $\bar{\alpha}$ is the average absorption coefficient and $S_{0}$ is the surface area of the space in which the noise source is located. By rearranging the Equation (1) and divide the both side of equality by the references values and taking the logarithm from both sides of Equation (1), Equation (4) can be obtained.

$$
\begin{aligned}
& L_{W}=L_{P_{\text {ave }}}+10 \log _{10} \log _{10}\left(\frac{S_{m}}{S_{r e f}}\right)-K_{r}-10 \log _{10} \log _{10}\left(\frac{\rho_{0} c W_{r e f}}{P_{r e f}^{2} S_{r e f}}\right), \\
& S_{r e f}=1 m^{2}
\end{aligned}
$$

in which the parameter $K_{r}$ is defined as below,

$$
K_{r}=10 \log _{10} \log _{10}\left[1+\frac{4(1-\bar{\alpha}) S_{m}}{\bar{\alpha} \cdot S_{0}}\right]
$$

For air at standard condition, the last term of Equation (5) is approximately equal to 0.1 decibel (dB). So by measuring the sound pressure level the sound power level of the noise source can be obtained during each oper- 
ating condition by applying the Equation (5). By these data, the empirical relation between sound power level and the effecting designing and operating parameters can be derived. The major effective parameters which has been considered are the engine power, mass of hammers (mass of one hammer times the number of hammers) and angular velocity (rpm). Four crusher units have been studied in this survey. Three of them were the main stone crushers located in unpainted block rooms. The surface absorption coefficient of such a room is reported as 0.35 in Barron [17]. The other crusher was a mini crusher has been installed between kiln and cement mill units to operate on the clinker particles. It should be noted that the sub crusher is located in an open field in which the reverberant acoustic field is much lower than the direct field. So according to Barron [17], this environment can be dealt as an anechoic room and the sound power level calculation procedure is as below,

$$
W=\sum_{j} I_{j} S_{j}=\frac{S_{0} \cdot \sum P_{j}^{2}}{\rho_{0} \cdot C \cdot N_{s}}
$$

where $j$ is counter on the number of measuring points. The total area of the hemisphere commonly has been divided to $N_{s}$ equal surfaces. Here the value of $N_{s}$ is selected as 6. $\rho_{0}$ and $C$ are the air mass density and sound velocity in the air in the operating condition $\left(0.98 \mathrm{~atm}\right.$. and $\left.40^{\circ} \mathrm{C}\right)$ respectively. $P_{j}$ is the SPL at point $j$ in Pascal.

The SPL of four crusher units has been measured $300 \mathrm{~mm}$ away from the source. And based on the noted equations the sound power level has been calculated. Some feathers of the crushers and the result of power level calculation have been summarized in Table 3 .

Because of the logarithmic relation between the independent effective parameters and the acoustic features in most empirical equations (Heitner [27], Nakano [28]) and also ease of use of the level type of parameters in acoustic field, the mathematical correlation among the sound power level and the effective parameters, has been considered as Equation (7).

$$
L_{w}=A+B * \log \left(\frac{h p}{h p_{0}}\right)+C * \log \left(\frac{M_{h}}{M_{h 0}}\right)
$$

in which $h p$ and $M_{h}$ are the horsepower of crusher and the mass of hammers respectively. $h p_{0}$ and $M_{h 0}$ are the reference values of the noted parameters which have been set to 1 . The angular velocity for all four crushers was $1000 \mathrm{rpm}$. So its effect on $L_{w}$ cannot be considered in this case. The value of constant $A$ in Equation (7) can be a representative which implicitly show the effect of some operating and design parameters have not been considered here.

Using the data in Table 3 and the proposed Equation (7), a multiple regression algorithm by minimizing the mean square error has been used to calculate the unknown coefficients in Equation (7). The unknown coefficients $A, B$ and $C$ in Equation (7) have been obtained 15, 10 and 17 respectively. By the obtained coefficients, the predicted value of $L_{W}$ has been calculated by Equation (7) and compared with the measured values in Figure 4. As it can be seen, there is a reliable consistency between the predicted values by the proposed equation and the measured data. It should be noted that by measuring more data in different factories with diverse types of crushers, the effect of other physical parameters like angular velocity, capacity of the machine and the aspect ratio of stone can be highlighted. This plan is one of our next goals in this research area.

\section{Conclusion}

In this work a survey analysis has been done in the Tehran cement factory to find the noisiest sources which

\begin{tabular}{|c|c|c|c|c|c|c|c|c|}
\hline $\begin{array}{l}\text { Parameter } \\
\text { Unit }\end{array}$ & Dimensions & Hammer No. & $\begin{array}{l}\text { Mass of Hammer } \\
(\mathrm{kg})\end{array}$ & $M_{h}(\mathrm{~kg})$ & Sample No. & $h p$ & $L_{W}(\mathrm{~dB})$ & $\begin{array}{c}\text { Room } \\
\text { dimensions }\end{array}$ \\
\hline Stone crusher 1 & $2 \times 1 \times 2$ & 70 & 75 & 5250 & 9 & 1502 & 111.8 & $8 \times 8 \times 3$ \\
\hline Stone crusher 2 & $3 \times 2 \times 3$ & 84 & 120 & 1080 & 9 & 1745 & 117.4 & $10 \times 10 \times 4$ \\
\hline Stone crusher 3 & $3 \times 2 \times 2$ & 70 & 90 & 6300 & 9 & 805 & 106.4 & $12 \times 6 \times 3$ \\
\hline Sub crusher 1 & $2 \times 1 \times 1$ & 60 & 52 & 3120 & 6 & 422 & 102.3 & - \\
\hline
\end{tabular}

Table 3. Measured sound power level and some parameters of the crushers. 


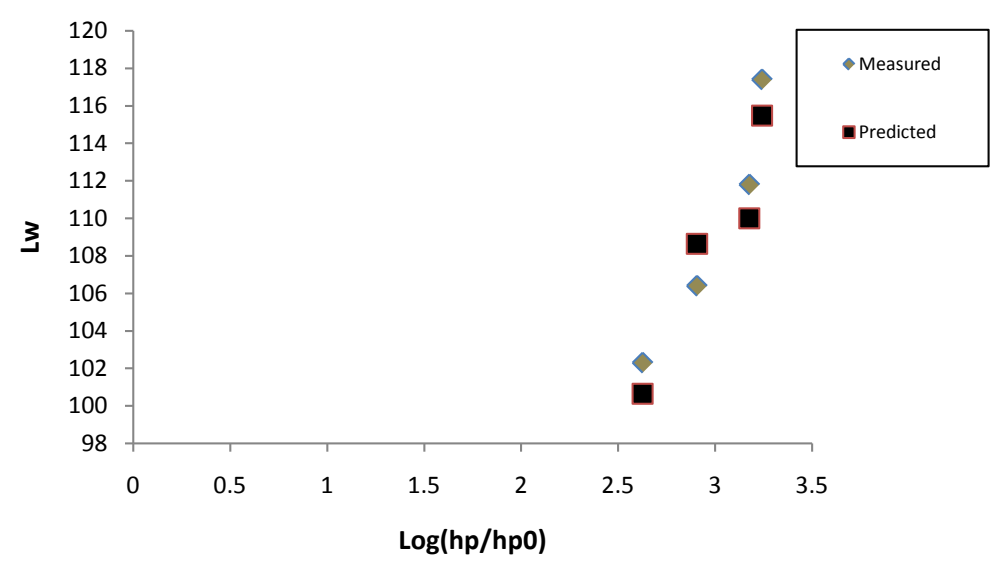

(a)

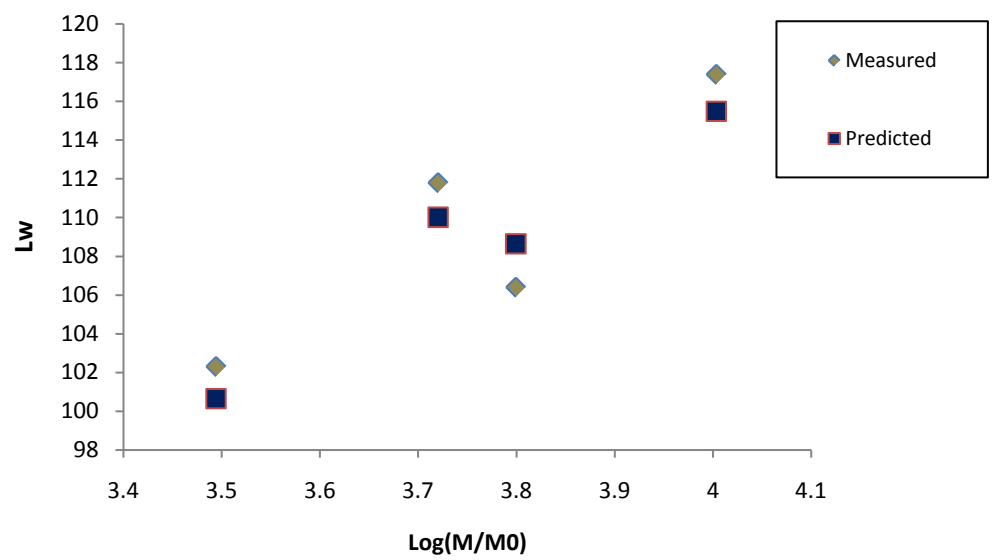

(b)

Figure 4. (a) Measured and predicted values of $L_{W}$ versus horsepower; (b) Measured and predicted values of $L_{W}$ versus total hammers' mass.

emit the noise in workers main commuting spots. The acoustic measurement results show that the crusher, cement mill and row mill units are the three major noise emission sources. In the another experiment, based on the ANSI S1.36 and ISO 3746 guidelines, the sound power level of the crusher unit has been measured indirectly. Afterwards, by using a multiple regression algorithm and minimizing the mean square error, an empirical equation has been proposed to correlate the acoustic power level as a function of the horsepower and the mass of all hammers of the crusher.

\section{References}

[1] Eleftheriou, P.C. (2002) Industrial Noise and Its Effects on Human Hearing. Applied Acoustics, 63, 5-42. http://dx.doi.org/10.1016/S0003-682X(01)00022-6

[2] (2005) Tanzania Bureau of Standards (TBS). ACOUSTICS-General Tolerance Limits for Environmental Noise, National Environmental Standards Compendium, EMDC 6, No. 2, 1733.

[3] (2005) The Control of Noise at Work Regulations (S.I. 2005/1643). Health and Safety.

[4] (1998) National Institute for Occupational Safety and Health (NIOSH). Criteria for a Recommended Standard: Occupational Noise Exposure. US Department of Health and Human Services, Center for Disease Control and Prevention, Cincinnati.

[5] Melamed, S., Fried, Y. and Froom, P. (2001) The Interactive Effect of Chronic Exposure to Noise and Job Complexity on Changes in Blood Pressure and Job Satisfaction: A Longitudinal Study of Industrial Employees. Journal of Occupational Health Psychology, 6, 182-195. http://dx.doi.org/10.1037/1076-8998.6.3.182

[6] Rick, N. (2004) Noise Exposure Standards around the World [Monograph on the Internet]. University of Washington, 
Washington.

[7] Sharma, O., Mohanan, V. and Singh, M. (1998) Noise Emission Levels in Coal Industry. Applied Acoustics, 54, 1-7. http://dx.doi.org/10.1016/S0003-682X(97)00073-X

[8] Zhang, C.F., Yuan, S.J. and Li, D. (2012) Comprehensive Control of the Noise Occupational Hazard in Cement Plant. Procedia Engineering, 43, 186-190. http://dx.doi.org/10.1016/j.proeng.2012.08.032

[9] Asdrubali, F. and Baldinelli, G. (2003) Acoustic Impact Evaluation and Mitigation of Cement Production Plants. 32nd International Congress and Exposition on Noise Control Engineering JEJU International Convention Center, Seogwipo, 25-28.

[10] Ghotbi Ravandi, M.R., Nadri, F., Khanjani, N. and Ahmadian, M. (2012) Occupational Noise Exposure among the Workers of Kerman Cement Plant. JOHE, 1, 17-23.

[11] Heitner, I. (1968) How to Estimate Plant Noises. Hydrocarbon Processing, 47, 67-74.

[12] Ellis, R.M. (1971) Cooling Tower Noise Generation and Radiation. Journal of Sound and Vibration, 16, 171-182. http://dx.doi.org/10.1016/0022-460X(71)90382-8

[13] Makarewicz, R. (2012) Generation Parameter of a Road Vehicle. Applied Acoustics, 73, 610-613. http://dx.doi.org/10.1016/j.apacoust.2011.12.014

[14] Jones, R.R.K. and Hothersall, D.C. (1980) Effect of Operating Parameters on Noise Emission from Individual Road Vehicles. Applied Acoustics, 13, 121-136. http://dx.doi.org/10.1016/0003-682X(80)90028-6

[15] (1986) ISO, Acoustics-Determination of Sound Power Levels of Noise Sources-Survey Method. International Organization for Standardization, Geneva, ISO 3746.

[16] Mndeme, F.G. and Mkoma, S.L. (2012) Assessment of Work Zone Noise Levels at a Cement Factory in Tanga, Tanzania. EJESM, 5, 225-231.

[17] Barron, F.R. (2001) Industrial Noise Control and Acoustics. Marcel Dekker, New York.

[18] Acoustical Society of America (1986) Precision Methods for the Determination of Sound Power Levels of Broad-Band Noise Sources in Reverberation Rooms. Acoustical Society of America, Woodbury, ANSI S1.31.

[19] Acoustical Society of America (1986) Precision Methods for the Determination of Sound Power Levels of Discrete Frequency and Narrow-Band Noise Sources in Reverberation Rooms. Acoustical Society of America, Woodbury, ANSI S1.32.

[20] Acoustical Society of America (1986) Engineering Methods for the Determination of Sound Power Levels of Noise Sources in a Special Reverberation Test Room. Acoustical Society of America, Woodbury, ANSI S1.33.

[21] Acoustical Society of America (1979) Precision Methods for the Determination of Sound Power Levels of Noise Sources in Anechoic and Hemi-Anechoic Rooms. Acoustical Society of America, Woodbury, ANSI S1.35.

[22] (1986) ISO, Acoustics Determination of Sound Power Levels of Noise Sources-Broad-Band Sources in Reverberation Rooms. International Organization for Standardization, Geneva, ISO 3741.

[23] (1986) ISO, Acoustics-Determination of Sound Power Levels of Noise Sources-Discrete-Frequency and Narrow-Band Sources in Reverberation Rooms. International Organization for Standardization, Geneva, ISO 3742.

[24] (1986) ISO, Acoustics-Determination of Sound Power Levels of Noise Sources-Special Reverberation Test Rooms. International Organization for Standardization, Geneva, ISO 3743.

[25] (1986) ISO, Acoustics-Determination of Sound Power Levels of Noise Sources-Anechoic and Semi-Anechoic Rooms. International Organization for Standardization, Geneva, ISO 3745.

[26] Acoustical Society of America (1979) Survey Methods for the Determination of Sound Power Levels of Noise Sources. Acoustical Society of America, Woodbury, ANSI S1.36.

[27] Heitner, I. (1968) How to Estimate Plant Noises. Hydrocarbon Processing, 47, 67-74.

[28] Nakano, A. (1968) Characteristics of Noise Emitted by Valves. 6th International Congress of Acoustics, Tokyo. 